satisfied with the teaching provided. In the group with access to the Moodle induction tutorial there was a $51 \%$ response to the surveymonkey (22/43) 36\% had heard of the MN-CMS project, $59 \%$ had used and EHR, but only $22 \%$ were aware of the induction tutorial. $76 \%$ were satisfied with the teaching provided. The students polled after access to the Moodle induction video were more likely to want access to a precourse induction $(50 \%$ vs $40 \%)$ as opposed to a first day classroom induction (50\% vs 60\%). Half of the students in the second group wished for an expanded Moodle induction.

Conclusion Comments from the first group suggested that it would be valuable to have the induction online. When accessed the Moodle hosted induction tutorial was well received and students found the material useful. There was a disappointing response to the surveymonkey questionnaire as compared to the paper classroom version which may underscore the benefit of the online tutorial. Based on these findings incoming students will receive precourse email notification of the tutorial and a repeat assessment will be performed.

\section{P244 PAEDIATRIC LIAISON PSYCHIATRY - ARE STUDENTS AWARE OF THE OVERLAP WITH MENTAL AND PHYSICAL HEALTH?}

${ }^{1} \mathrm{SC}$ Richardson*, ${ }^{1} \mathrm{ON}$ Oketah, ${ }^{1} \mathrm{H}$ Negm, ${ }^{1,2} \mathrm{E}$ Barrett. ${ }^{1}$ Temple Street University Hospital, Dublin, Ireland; ${ }^{2}$ University College Dublin, Dublin, Ireland

\subsection{6/archdischild-2019-epa.594}

Aim To assess medical students' knowledge and expectations pre and post a structured teaching session regarding mental health needs of young people in hospital. The objective is to analyse the effectiveness of the teaching session and to modify the teaching pack accordingly.

Methods Fifth year medical students were given a survey to complete at the start of a 3 hour teaching session on mental health needs of children in hospital. Students were asked basic knowledge questions and their learning objectives. The students were surveyed again at the end of the teaching to review if the learning outcomes were met and if basic knowledge had improved.

Results $87 \%$ (34/39) of the pre-teaching questionnaires and $77 \%$ (30/39) post teaching were completed. Fourteen students were graduate entry while the remainder were undergraduates. Several learning objectives were identified including understanding and management of Eating Disorders, understanding the differences between presentations in adults and children, and management of suicidal ideation and self-harm. Clinical questions and accurate response rate are outlined in table 1.

\begin{tabular}{lll} 
Abstract P244 Table 1 & & \\
\hline Clinical questions & $\begin{array}{l}\text { Correct Answer } \\
\text { pre-teaching }\end{array}$ & $\begin{array}{l}\text { Correct answer } \\
\text { post teaching }\end{array}$ \\
\hline Definition of Liaison Psychiatry & $41 \%(14 / 34)$ & $83 \%(25 / 30)$ \\
Definition of Psychosomatic disorder & $61.7 \%(21 / 34)$ & $96 \%(27 / 28)$ \\
Physical symptoms of severe weight loss & $29 \%(10 / 34)$ & $65.5 \%(19 / 29)$ \\
Physical symptoms of depression & $94 \%(32 / 34)$ & $96 \%(27 / 28)$ \\
Most common method of self - harm & $6.6 \%(2 / 30)$ & $78.5 \%(22 / 28)$ \\
\hline
\end{tabular}

In terms of qualitative feedback, most students found their learning objectives had been met. Case based discussion and interaction were valued. However, others reported overlaps with the adult psychiatry curriculum and disliked aspects of the format.

Conclusion Despite subject topics being available in advance, there was an evident lack of knowledge in some areas. Interactive case base approaches were preferred by students. Qualitative feedback highlighted aspects of the teaching which students found unhelpful and has led to modification of the lectures for further groups and a change in structure of the session for future medical students in the medical school.

\section{P245 ENHANCING CPD, QUALITY IMPROVEMENT AND BEST PRACTICE}

1,2Hilary Hoey*, 'Holly Hanlon, 'Thelma Russell, 'Deirdre Donegan, 'Lucia Prihodova, ${ }^{1}$ Ann O'Shaughnessy. 'Royal College of Physicians of Ireland, Dublin, Ireland; ${ }^{2}$ University of Dublin Trinity College, Dublin, Ireland

\subsection{6/archdischild-2019-epa.595}

Since 2011 recording of Continuing Professional Development (CPD) activities is mandatory in Ireland.Doctors must participate in a range of learning activities reflecting their scope of practice and include the 8 Domains of Good Professional Practice. Each year they must achieve 50 CPD credits (20 External, 20 Internal, 5 Personal Learning and 5 flexible) along with conducting a Clinical Audit. Construction of a Personal Development Plan (PDP) is recommended, but not mandatory.

The Royal College of Physicians of Ireland provides a Professional Competence Programme in Paediatrics, Medicine, Obstetrics and Gynaecology, Pathology, Public Health and Occupational Medicine.

Purpose of the study Assess CPD credits achieved and percentage of participants who performed an audit. Identify areas of good practice and barriers preventing engagement in order to enhance CPD and engage participants.

Methods Data submitted electronically from 2011 to 2018 were analysed using SPSS. In 2018, participants were requested to complete a 28 item questionnaire regarding perceived barriers, their recommendations to improve engagement and their desired relevant learning activities.

Results Number of participants enrolled increased each year from 2738 in 2012 to 4446 in 2018. Age range in 2018: 25-91 yrs (49\% aged $35-55$ yrs; $5 \%$ over 65 yrs), 54\% male.

CPD credits achieved along with completion of an audit increased each year. In 2017, 88\% of RCPI Fellows achieved $>50$ CPD Credits fulfilling all categories along with submitting an audit.

In 2016, 1381 (40.3\%) physicians completed a PDP. Those who completed a PDP were more likely to achieve $\geq 50$ credits $(\mathrm{p} \leq 0.001)$ and complete an audit $(\mathrm{p} \leq 0.001)$. Since 2017 early completion of a PDP has been incentivised with 2 Internal credits and the number completing a PDP increased from 1369 in 2016 to 1824 in 2018.

Physicians reported very positive perceptions regarding CPD with only $7 \%$ reporting it as a bad idea. Major barriers included time and finances to engage in CPD activities along with time required to record learning activities and obtain 